\title{
The Testing and Scoring of Some Avocado Varieties and New Selections on Their Behavior Under Refrigeration
}

\section{William Pennock ${ }^{1}$ \\ INTRODUCTION}

Avocado fruits must be both mature and ripe in order to attain good taste and palatability. Maturity is reached while the fruit is still attached to the tree and is simply a matter of aging. After fruit-set, a sufficiently long interval, ranging from 6 months to a year for most varieties, is necessary for the fruit to undergo the changes required to develop a potential for good flavor. Ripening, on the other hand, is the process whereby the flesh becomes soft and palatable and the potential flavor is realized. The ripening process usually starts when the fruit is picked and may take place irrespective of whether the fruit has reached maturity. Mature avocados generally ripen in 3 to 7 days at room temperature. This ripening period can be lengthened somewhat by picking the fruit slightly immature, but usually at the sacrifice of flavor. At best, the ripening period can be extended up to a length of 10 to 12 days at room temperature. Moreover, it would be most difficult to judge the maturity of all fruits so precisely as to avoid the early ripening of some few which, in turn, would hasten the ripening of other fruits in their immediate vicinity.

A minimum ripening period of about 15 days is required for the export and sale of Puerto Rican avocados in the United States markets, and a longer period is highly desirable. The fruit should reach the retail outlet quite firm without any perceptible degree of ripeness. Even slight softening will result in its disposal as distress merchandise at prohibitively low prices. The ripening period of avocados must be extended for their successful exportation which can best be done by means of refrigeration.

Refrigeration must be carefully controlled, however, because avocados are subject to cold injury. Moreover, selected varieties should be used for export because some varieties are highly susceptible to such injury even under mild refrigeration, whereas others are quite resistant and capable of having their ripening period considerably prolonged by storage at relatively low temperatures.

\section{REVIEW OF THE LITERATURE}

Although successful avocado storage at lower temperatures has frequently been reported, recent workers appear to be in general agreement

\footnotetext{
${ }^{1}$ Horticulturist, Agricultural Experiment Station. University of Puerto Rico, Rio Piedras, P.R.
} 
with the recommendation of Higgins, Hunn, and Holt made in $1911(1)^{2}$ that temperatures for avocado storage should not be permitted to fall below $40^{\circ} \mathrm{F}$. Commercial shipments are generally made at storage temperatures that range between $40^{\circ}$ and $50^{\circ} \mathrm{F}$. In Puerto Rico the shipper has the option of shipping at either $40^{\circ}$ to $45^{\circ} \mathrm{F}$., or $45^{\circ}$ to $50^{\circ} \mathrm{F}$.; both of these ranges are available in separate compartments of most boats having refrigerating facilities.

Cold injury or "chilling" has been reported by Wardlaw and Leonard ( 5 ) as including such various symptoms as follows: 1 , Skin-browning and necrosis; 2 , browning of the flesh; 3 , browning of the vascular strands; 4 , browning of the seed; and 5, changes in flavor. Following the lead of Lynch and Stahl ( 8 ) we have preferred to ignore the possible injury to either the skin or the seed and to lump the others and treat them as a single manifestation of cold injury occurring in the pulp. As described by Lynch and Stahl, "The browning of the pulp appears in some instances either near the seed or in the tissue midway between the seed and the skin. In other instances the pulp becomes dark brown to black next to the seed, and in still other cases the vascular strands develop a brownish appearance making them stand out from the lighter colored pulp". This description coincides very well with the symptoms observed by us. We were impressed, however, by the variation in severity of the injury which ranged from a barely perceptible trace of browning to a thorough blackening of the flesh accompanied by a disagreeable smell. To some extent, at least, cold injury seemed to be the result of a cumulative process which could be increased by either lowering the temperature or increasing the time of exposure.

Although some authors, e.g. Lyle (2) and Overholser (4), reported longer storage, we have estimated the optimum period as 30 days for temperatures which do not drop below $40^{\circ} \mathrm{F}$. at any time. Undoubtedly longer storage is feasible with a few highly tolerant varieties held at lower temperatures. However, even slightly lower temperatures would be quite hazardous for most varieties, and they are not available commercially. A minimum storage temperature of $40^{\circ} \mathrm{F}$. is sufficiently low to establish differences in cold tolerance for all commercial varieties now grown in Puerto Rico and probably elsewhere in the world.

\section{OBJECTIVES}

Our objectives were to establish a fairly precise procedure whereby varieties may be rated on their relative tolerance to cold storage, and to rate available varieties and new selections accordingly.

2 Italic numbers in parentheses refer to Literature Cited, p. 49. 


\section{MATERIALS AND METHODS}

Refrigeration studies were carried out usually using 40 fruits of each variety to be tested and subjecting them to each of 8 storage treatments. The treatments consisted, respectively, of storage at room temperature until ripe, and storage for periods ranging from 1 to 4 weeks at an average temperature of $43^{\circ} \mathrm{F}$, and 1 to 3 weeks at an average temperature of $53^{\circ} \mathrm{F}$. A treatment of storage for 4 weeks at $53^{\circ} \mathrm{F}$. proved impracticable.

Both refrigerators had a fluctuation range of about $3^{\circ} \mathrm{F}$. A recording thermograph was placed in each refrigerated compartment at all times and a continuous record of temperature was obtained for all tests. Relative humidity was recorded in some of the tests and usually registered between 75 to 90 in both compartments. Room temperature was checked occasionally. It ranged from $75^{\circ}$ to $85^{\circ} \mathrm{F}$., but was fairly close to $80^{\circ} \mathrm{F}$., most of the time. Storage at room temperature was simply the control treatment and served principally as a rough index of maturity and also as a precaution against misinterpreting other normal storage injury or possibly a varietal defect as having been caused by cold injury. The data from room-temperature storage were not used in calculating refrigeration performance indices.

The number of fruits per treatment was reduced in a few instances when insufficient fruits were available. In other instances the fruit intended for 3- or 4-week storage periods was observed to have ripened prematurely and was, therefore, removed from the refrigerator together with, and included with the fruit in the corresponding shorter period. In such cases, therefore, 10 and sometimes 15 fruits provided the data for the shorter treatment. The fruit was generally harvested during the forenoon, transported in field crates, and placed in carboard flats in the refrigerator roughly about 24 hours after picking.

After the specified period of refrigerated storage, the fruit was removed to room temperature and allowed to ripen. Ripeness was determined by touch in most varieties, and by the "matchstick" method with hard-shelled fruit. The fruit was then sliced open, the seed removed and both halves examined carefully for degree of observable pulp-browning. Notes were taken regarding other symptoms but pulp browning was the only symptom of cold injury tabulated for this study and was coded as follows:

\section{Condition}

Points

No browning whatever

Traces of browning

Slight browning

Moderate browning

Badly browned 
The following descriptive notes may serve as a rough guide for interpreting what is meant by the different degrees of browning:

TRACES OF BROWNING

"Traces" referred to a barely perceptible brownish cast frequently occurring on the flesh surface adjacent to the seed cavity, or sometimes a very small brownish spot either on the flesh surface or on some vascular strand. When vascular strands were affected, frequent slicing of the flesh was made to determine the extent of the injury. Sometimes, particularly, in fruits held in cold storage more than 2 weeks, browning of the vascular strands was so faint as to be questionable. In such cases the peeled slices of fruit were allowed to stand in the open air for 1 or 2 minutes until the exposed surfaces became streaked with brown where the fibers showed. A fresh cut was then made and the freshly cut surface examined and judged for browning in the vascular strands. In summary, "traces of browning" would normally be overlooked by most people and require careful examination to detect. There is no off-flavor nor smell whatever.

\section{SLIGHT BROWNING}

"Slight browning" applies to the injury of fruits having readily observaable browning injury, but of such limited extent that three-fourths or more of the fruit was edible and of good appearance and flavor after paring off the injured part.

\section{MODERATE BROWNING}

"Moderate browning" applies to the injury of fruits in which approximately half of the flesh is browned and about half looks uninjured. Although parts of the fruit appear to be edible, all of it may actually be unfit for consumption since off-flavor frequently extends beyond the browned areas. This category also includes some fruits which may look uninjured, or almost so, but actually have off-flavor and/or unpleasant smell and are, therefore, unfit for consumption. This occurs, rather infrequently, with the fruit of some few varieties.

\section{BADLY BROWNED}

No part of the "badly browned" fruit looks edible and it usually has an offensive odor.

\section{SCORING}

The performance for all fruit subject to a single treatment was recorded and converted to two numbers as follows:

1. The "day number", or the sum of the number of days required by each fruit to ripen. 
2. The "browning number", or the total code points scored by all the fruits in the treatment.

These two numbers were then individually converted into index numbers denoting that fraction of a perfect performance attained by the fruit with respect to ripening period on the one hand and browning injury on the other. These two index numbers were then multiplied by each other. The products thus obtained were regarded as a sort of dual index for each treatment whose mean constitutes a single generalized index of performance for each set of fruit tested.

Altogether we tested 36 sets of fruits. Each set usually was of a different variety or clonal selection, but on several occasions a variety was tested twice and on one occasion three times, using fruit from different trees. In some cases, because of fruit scarcity, we were obliged to include the fruit from several trees of the same variety in one set of fruit being tested. In such cases this was done systematically so that an equal number from each tree received the different storage treatments.

\section{RESULTS OBTAINED}

In table 1 are shown the original data pertaining to flesh browning and days required to ripen in terms of totals for all the fruit included in each treatment. Also shown are the harvest dates, the clones being tested, the individual tree identity number, and the fruit number included in each treatment. As may be seen, some sets of fruit being tested were not subjected to all of the treatments. The first seven clones, for example, were all early varieties mostly of the West Indian race. These were not expected to withstand 3 weeks of storage or more, and therefore, their testing was limited to the first 2 weeks. In some cases the fruit intended to remain for 3 and 4 weeks at $53^{\circ} \mathrm{F}$. was found to be ripe when examined at the end of the 2-week period. Such fruit was included with the 2-week fruit at this temperature.

A rough idea of the relative maturity may be obtained from the time required by the fruit to ripen when stored at room temperatures. The fruit of tree No. 363 of clone Semill 44, harvested on December 5, for example, may be regarded as having been somewhat immature because the four fruits delayed an accumulated a total of 39 days or an average of 10 days per fruit. The fruit of tree No. 108 of clone Gripiña 9, harvested on September 26 , on the other hand, was obviously thoroughly mature since the ripening period averaged 3 days per fruit.

In tables 2 and 3, respectively, are shown the ripening period and fleshbrowning indices derived from the data in table 1. These were calculated for refrigerated treatments only and may be regarded as a decimal number indicating that fraction of a perfect performance obtained in each case. 


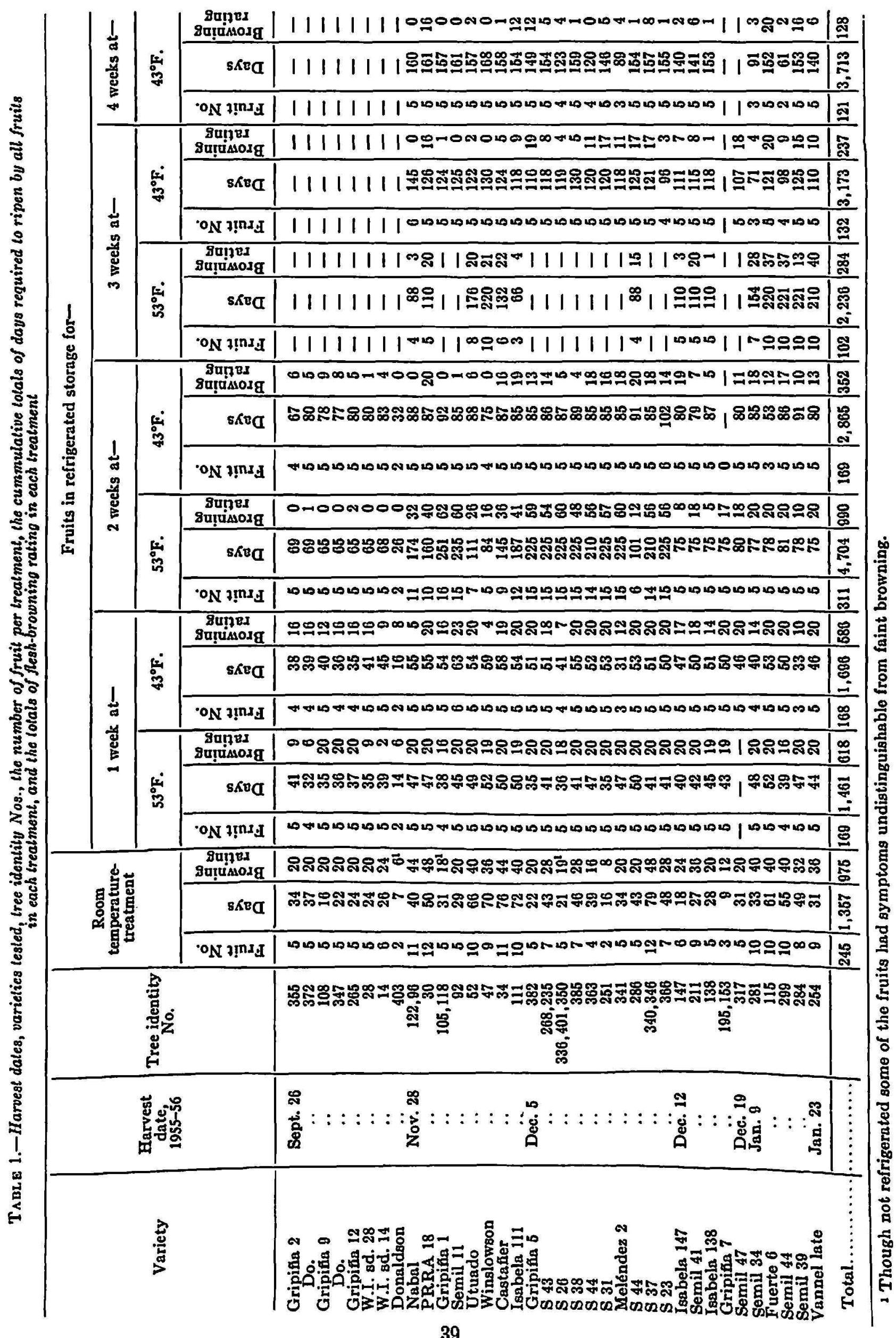


TABLE 2.-Flesh-browning index of different avocado varieties from different trees when held under refrigeration at $49^{\circ}$ and $53^{\circ} \mathrm{F}$. for 1 to 4 weeks

\begin{tabular}{|c|c|c|c|c|c|c|c|c|}
\hline \multirow{3}{*}{ Variety } & \multirow{3}{*}{ Tree No. } & \multicolumn{7}{|c|}{ Fruit in refrigerated storage for- } \\
\hline & & \multicolumn{2}{|c|}{1 week at- } & \multicolumn{2}{|c|}{2 weeks at- } & \multicolumn{2}{|c|}{3 weeks at -} & \multirow{2}{*}{$\begin{array}{l}4 \text { weeks } \\
\text { at } 43^{\circ} \mathrm{F}\end{array}$} \\
\hline & & $53^{\circ} \mathrm{F}$. & $43^{\circ} \mathrm{F}$ & $53^{\circ} \mathrm{F}$ & $43^{\circ} \mathrm{F}$ & $53^{\circ} \mathrm{F}$ & $43^{\circ} \mathrm{F}$. & \\
\hline Gripiña 2 & 355 & 450 & $1-$ & 0 & 375 & - & - & 一 \\
\hline Do. & 372 & 375 & $1-$ & 050 & 250 & - & - & - \\
\hline Gripiña 9 & 108 & $1-$ & 600 & 0 & 450 & - & - & - \\
\hline Do. & 347 & $1-$ & $1-$ & 0 & 400 & 一 & - & - \\
\hline Gripiña 12 & 265 & $1-$ & $1-$ & 100 & 250 & 一 & - & 一 \\
\hline W. I sd. 28 & 28 & 450 & 800 & 0 & 50 & - & - & 一 \\
\hline W. I sd. 14 & 14 & $1-$ & 450 & 0 & 200 & 一 & - & 一 \\
\hline Donaldson & 403 & 750 & $1-$ & 0 & 400 & - & - & 一 \\
\hline Nabal & 122,96 & $1-$ & 250 & 727 & 0 & 188 & 0 & 0 \\
\hline PRRA 18 & 30 & $1-$ & $1-$ & $1-$ & $1-$ & $1-$ & 800 & 800 \\
\hline Gripiña 1 & 105,118 & $1-$ & 800 & 969 & 0 & - & 50 & 0 \\
\hline Semil 11 & 92 & $1-$ & 958 & $1-$ & 50 & - & 0 & 0 \\
\hline Utuado & 52 & $1-$ & $1-$ & 929 & 300 & 625 & 100 & 100 \\
\hline Winslowson & 47 & 950 & 200 & 800 & 0 & 525 & 00 & 0 \\
\hline Castañer & 34 & $1-$ & 950 & $1-$ & 800 & 917 & 250 & 50 \\
\hline Isabela 111 & 111 & 950 & $1-$ & 854 & 950 & 333 & 450 & 600 \\
\hline Gripiña 5 & 382 & $1-$ & $1-$ & 983 & 650 & - & 950 & 600 \\
\hline Semil 43 & 268,235 & $1-$ & 900 & 900 & 700 & 一 & 400 & 250 \\
\hline Semil 26 & $336,401,350$ & 900 & 438 & $1-$ & 250 & - & 200 & 250 \\
\hline Semil 38 & 385 & $1-$ & $1-$ & 800 & 200 & - & 250 & 250 \\
\hline Semil 44 & 363 & 1 & 1 & $1-$ & 900 & - & 550 & 0 \\
\hline Semil 31 & 251 & 1 & 1 & 950 & 800 & - & 850 & 250 \\
\hline Meléndez 2 & 341 & 1 & 1 & $1-$ & 900 & - & 550 & 333 \\
\hline Semil 44 & 286 & $1-$ & $1-$ & 500 & $1-$ & 938 & 850 & 050 \\
\hline Semil 37 & 340,346 & 1 & 1 & $1-$ & 900 & - & 850 & 400 \\
\hline Semil 23 & 366 & $1-$ & 1 & 930 & 583 & - & 188 & 50 \\
\hline Isabela 147 & 147 & 1 & 850 & 400 & 950 & 150 & 350 & 100 \\
\hline Semil 41 & 211 & $1-$ & 900 & 900 & 350 & $1-$ & 400 & 300 \\
\hline Isabela 138 & 138 & 950 & 700 & 250 & 250 & 050 & 50 & 50 \\
\hline Gripiña 7 & 195,153 & 950 & 10 & 850 & - & - & - & - \\
\hline Semil 47 & 317 & 800 & $1-$ & 900 & 550 & - & 900 & - \\
\hline Semil 34 & 281 & 1 & 875 & $1-$ & 900 & $1-$ & 333 & 250 \\
\hline Fuerte 6 & 115 & 1 & 1 & 1 & $1-$ & 925 & $1-$ & $1-$ \\
\hline Semil 44 & 299 & 1 & $1-$ & $1-$ & 850 & 925 & 563 & 250 \\
\hline Semil 39 & 284 & $1-$ & 833 & 500 & 500 & 325 & 750 & 800 \\
\hline Vannel late & 254 & 1 & 10 & $1-$ & 650 & 100 & 500 & 300 \\
\hline Total. & & 31,825 & 26,504 & 24,392 & 18,058 & 9,903 & 12,134 & 6,833 \\
\hline $\mathrm{Me}$ & & 909 & 92 & 930 & 948 & 340 & 955 & 737 \\
\hline
\end{tabular}


TABLE 3.-Number-of-days ripening-period index for different avocado varieties from different trees held under refrigeration at $48^{\circ}$ and $58^{\circ} F$. for 1 to 4 weeks

\begin{tabular}{|c|c|c|c|c|c|c|c|c|}
\hline \multirow{3}{*}{ Variety } & \multirow{3}{*}{ Tree No. } & \multicolumn{7}{|c|}{ Fruit in refrigerated storage for- } \\
\hline & & \multicolumn{2}{|c|}{1 week at- } & \multicolumn{2}{|c|}{2 weeks at- } & \multicolumn{2}{|c|}{3 weeks at- } & \multirow{2}{*}{$\begin{array}{l}4 \text { weeks } \\
\text { at } 43^{\circ} \mathrm{F}\end{array}$} \\
\hline & & $53^{\circ} \mathrm{F}$ & $43^{\circ} \mathrm{F}$ & $53^{\circ} \mathrm{F}$. & $43^{\circ} \mathrm{F}$. & $53^{\circ} \mathrm{F}$. & $43^{\circ} \mathrm{F}$. & \\
\hline Gripiña 2 & 355 & 273 & 317 & 460 & 558 & 一 & - & - \\
\hline Do. & 372 & 267 & 325 & 460 & 533 & 一 & 一 & - \\
\hline Gripiña 9 & 108 & 233 & 267 & 433 & 520 & 一 & 一 & 一 \\
\hline Do. & 347 & 240 & 300 & 433 & 513 & - & 一 & - \\
\hline Gripiña 12 & 265 & 247 & 292 & 433 & 533 & 一 & 一 & 一 \\
\hline W. I sd. 28 & 28 & 233 & 273 & 433 & 533 & 一 & - & - \\
\hline W. I sd. 14 & 14 & 260 & 300 & 453 & 553 & - & - & 一 \\
\hline Donaldson & 403 & 233 & 267 & 433 & 533 & - & 一 & - \\
\hline Nabal & 122,96 & 313 & 367 & 527 & 587 & 733 & 806 & 1,067 \\
\hline PRRA 18 & 30 & 313 & 367 & 533 & 580 & 733 & 840 & 1,073 \\
\hline Gripiña 1 & 105,118 & 317 & 360 & 523 & 613 & - & 827 & 1,047 \\
\hline Semil 11 & 92 & 300 & 350 & 522 & 567 & 一 & 833 & 1,073 \\
\hline Utuado & 52 & 327 & 360 & 529 & 587 & 733 & 813 & 1,047 \\
\hline Winslowson & 47 & 347 & 393 & 560 & 625 & 733 & 867 & 1,120 \\
\hline Castañer & 34 & 333 & 387 & 537 & 580 & 733 & 827 & 1,053 \\
\hline Isabela 111 & 111 & 333 & 360 & 519 & 567 & 733 & 787 & 1,027 \\
\hline Gripiña 5 & 382 & 233 & 340 & 500 & 567 & - & 773 & 993 \\
\hline Semil 43 & 268,235 & 273 & 340 & 500 & 573 & - & 787 & 1,027 \\
\hline Semil 26 & $336,401,350$ & 240 & 342 & 500 & 580 & - & 793 & 1,025 \\
\hline Semil 38 & 385 & 273 & 367 & 500 & 593 & 一 & 867 & 1,060 \\
\hline Semil 44 & 363 & 313 & 347 & 500 & 567 & - & 800 & 1,000 \\
\hline Semil 31 & 251 & 233 & 353 & 500 & 567 & 一 & 800 & 973 \\
\hline Meléndez 2 & 341 & 313 & 344 & 500 & 567 & - & 787 & 989 \\
\hline Semil 44 & 286 & 333 & 353 & 561 & 607 & 733 & 833 & 1,027 \\
\hline Semil 37 & 340,346 & 273 & 340 & 500 & 567 & - & 807 & 1,047 \\
\hline Semil 23 & 366 & 273 & 333 & 500 & 567 & - & 800 & 1,033 \\
\hline Isabela 147 & 147 & 267 & 313 & 500 & 533 & 733 & 740 & 933 \\
\hline Semil 41 & 211 & 280 & 333 & 500 & 527 & 733 & 767 & 940 \\
\hline Isabela 138 & 138 & 300 & 340 & 500 & 580 & 733 & 787 & 1,020 \\
\hline Gripiña 7 & 195,153 & 287 & 333 & 500 & - & - & - & - \\
\hline Semil 47 & 317 & - & 307 & 533 & 533 & - & 713 & 一 \\
\hline Semil 34 & 281 & 320 & 333 & 513 & 567 & 733 & 789 & 1,011 \\
\hline Fuerte 6 & 115 & 347 & 353 & 520 & 589 & 733 & 807 & 1,013 \\
\hline Semil 44 & 299 & 325 & 333 & 540 & 573 & 737 & 817 & 1,017 \\
\hline Semil 39 & 284 & 313 & 367 & 520 & 607 & 737 & 833 & 1,020 \\
\hline Vannel late & 254 & 293 & 307 & 500 & 533 & 700 & 733 & 933 \\
\hline Total. & & 10,058 & 12,063 & 17,975 & 19,759 & 10,970 & 21,633 & 26,568 \\
\hline $\mathrm{Me}$ & & 287 & 345 & 514 & 565 & 731 & 801 & 1,022 \\
\hline
\end{tabular}




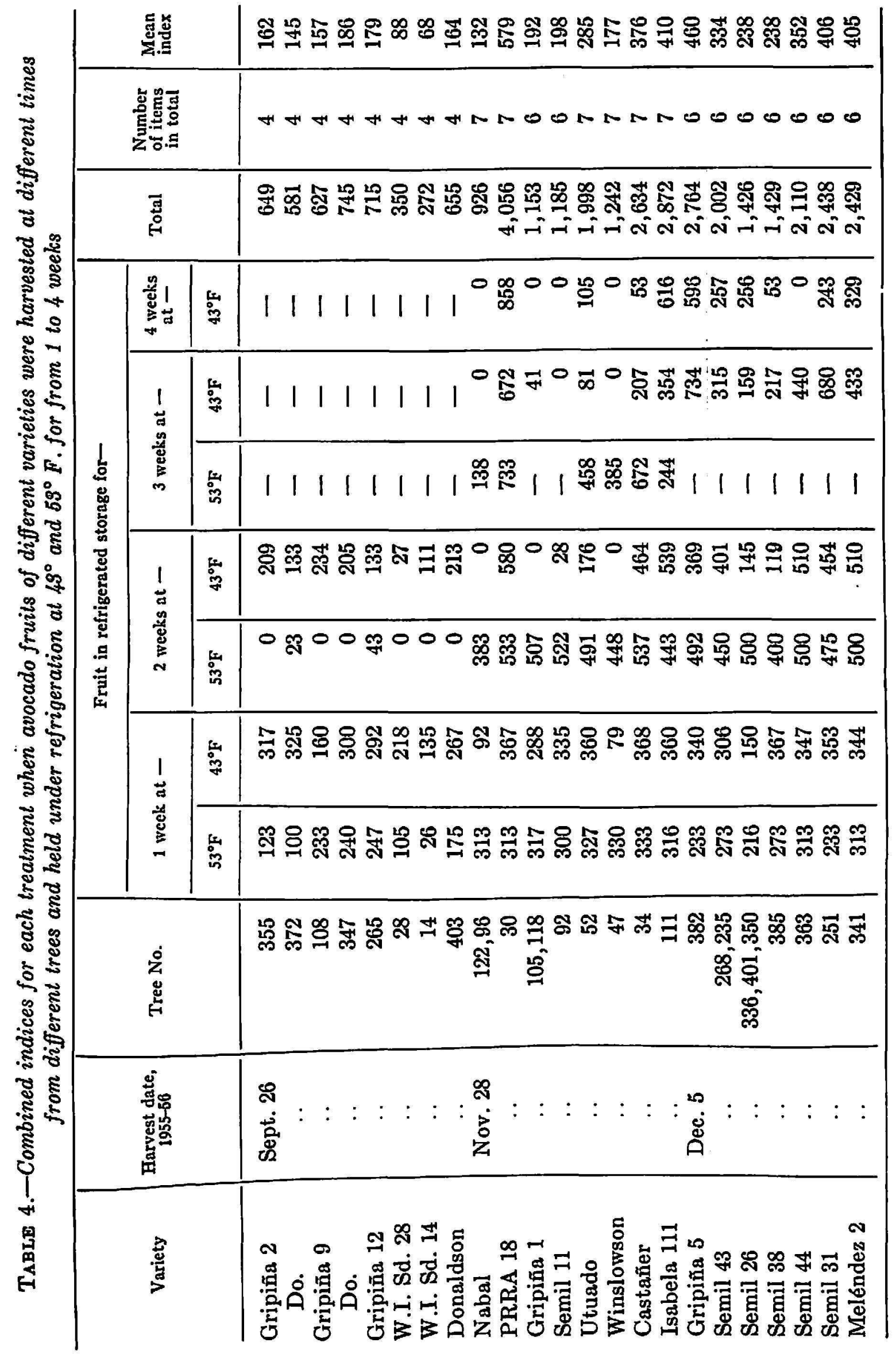




\begin{tabular}{|c|c|c|}
\hline & & 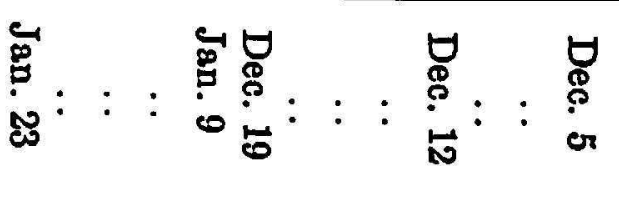 \\
\hline & & 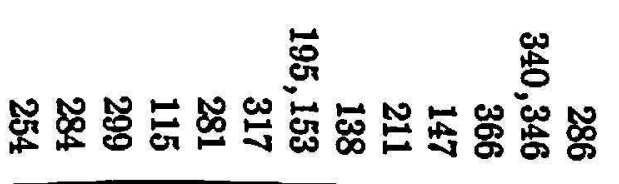 \\
\hline$q$ & | & 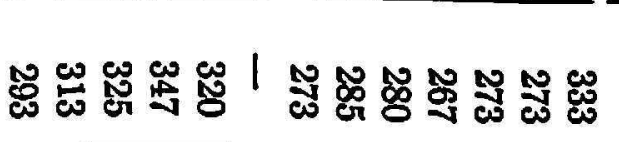 \\
\hline & $\begin{array}{l}0 \\
0 \\
0 \\
0\end{array}$ & 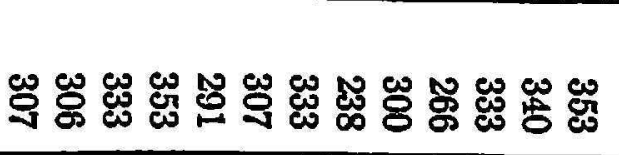 \\
\hline 幽 & 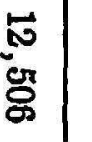 & 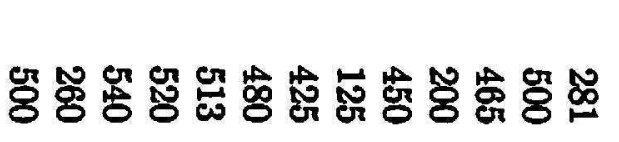 \\
\hline & | & 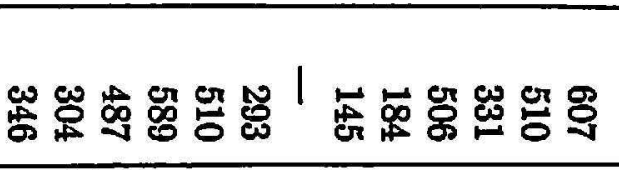 \\
\hline 悹\| & 䓌 & రิ \\
\hline$\stackrel{g}{g_{a}}$ & 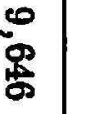 & 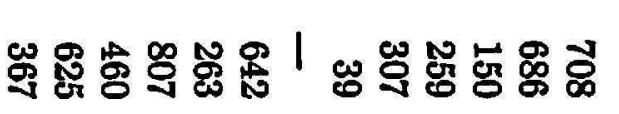 \\
\hline$\stackrel{\widetilde{s}}{\Im}$ & | & 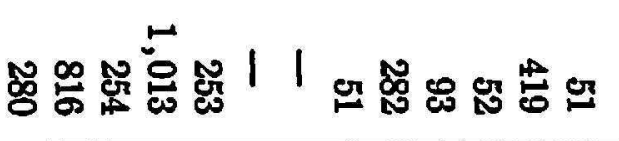 \\
\hline & 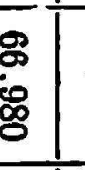 & 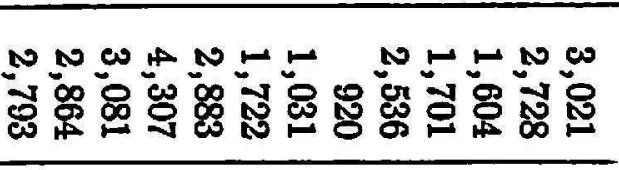 \\
\hline & & \\
\hline & & \\
\hline
\end{tabular}


With respect to flesh-browning, a perfect performance for a single fruit would be no browning whatever or a score of 4 . When multiplied by the number of fruits in the treatment this gives a perfect score for all the fruits. The browning totals shown in table 1 were divided by the perfect score and gave the figures shown in table 2.

A similar procedure was used in calculating the day indices. In this case a perfect score for a single fruit would be 30 days which was multiplied by the number of fruits to obtain the total perfect score. The day indices shown in table 3 were obtained by dividing the day totals shown in table 1 by the perfect score for total fruit in the treatment.

In table 4 are shown the combined indices for each treatment. These indices were obtained by multiplying the browning index and the day index for each treatment shown in tables 2 and 3 by each other and rounded off at 3 digits. The means of the combined indices is a generalized figure representing performance in all the refrigeration treatments to which the different clones were submitted.

\section{DISCUSSION}

\section{TESTING METHOD USED}

In testing avocados for cold-storage tolerance, multiple treatments are undoubtedly indicated. Any single treatment, if too severe, would fail to differentiate between varieties having low tolerance and, if too mild, between highly tolerant varieties. Since refrigeration is normally available for commercial shipment at two temperature ranges, $40^{\circ}$ to $45^{\circ} \mathrm{F}$. and $45^{\circ}$ to $50^{\circ} \mathrm{F}$., it seemed logical to include two similar ranges in the test, particularly since the lowest range might be injurious to some varieties even during only a few days of storage. The weehly intervals of storage were simply convenient and of sufficient duration to insure appreciable differences. The seven treatments used in these trials, therefore, seem fairly logical and coincide quite well with the range of tolerance of avocado fruits in general. We now believe mean temperatures of $42^{\circ}$ and $47^{\circ} \mathrm{F}$. would have been somewhat better than those actually used because, much less short-of-period ripening would probably have occurred in the 3-week treatment at the higher temperature and the 4-week treatment at the lower.

The general method of manipulating the data originally suggested by Associate Director B. G. Capó of this Station appears to be the only logical way of arriving at a generalized value for all treatments which would reflect both length-of-ripening period achieved and cold injury manifested by the fruit. We had some doubts whether to use directly the actual days required by the fruit to ripen, or the net increase in time gained over the 
control. The use of the net increase would cancel out the effect of possible variations in maturity. However, it would also cancel out the desirable capacity of some varieties which have good mature flavor coincident with a fairly long ripening period at room temperature. This capacity contributes to good shipping performance and, therefore, should preferably be retained as a partial constituent of the final varietal index. We decided that the actual period of days should be used for testing varieties and that the maturity factor should be eliminated by careful picking. If tests are made later for optimum refrigeration temperature, then net increase in ripening time may be preferable. In any case this point proved to be somewhat academic because it was observed that, in some lots of fruit which varied considerably in their individual ripening period at room temperature, the variation almost completely disappeared as cold storage was prolonged beyond 1 week.

We still have to determine by further experimentation the magnitude of the differences to be expected between fruit from the same tree in different years, and between different sets of fruit taken from the same tree in the same year, but on different and on the same harvest dates. However, there are in the present data three clones which were separately tested from two or more trees, namely Gripiña 2 and Gripiña 9, both of which were tested from two different trees on the same harvest date, and Semil 44 which was tested from two trees on the same date and from a third tree a month later.

As may be seen in table 5 there was a fairly high degree of consistency in the refrigeration-tolerance indices within clones and relatively little variance between trees and between harvest dates. With the clone Gripiña 2 there was a difference of only 17 points between trees; this was 11 percent of the mean clonal index, which was 154 , and 3 percent of the total range of variation between clones which amounted to 547. With clone Gripiña 9 the difference amounted to 29 points. This was 17 percent of the mean clonal index, which was 172 , and 5 percent of the range of variation between clones. In the clone Semil 44 the differences between the three trees amounted to 88,79 , and 9 points. These were 22,19 , and 2 percent, respectively, of the mean clonal index, which was 408 , and 16 , 14 , and 2 percent of the total range of variation between clones. It would appear, therefore, that there are marked clonal differences in refrigeration tolerance and the proposed refrigeration-tolerance indices give a fair indication of clonal refrigeration tolerance, irrespective of tree sampled or the time of fruit harvest within maturity limits.

We believe that the combined mean indices shown in table 4 are fairly reliable, precise, and convenient for rating and comparing the performance of avocado varieties under refrigerated storage. We propose to test all 
varieties accordingly and will refer to this mean index as the "varietal refrigeration tolerance index". The higher the index, of course, the better the performance. The absolute maximum index which any variety might attain would probably be about 0.628 . The variety would have to score index 1 on flesh condition in all treatments, making the day index identical with the combined index which would be approximately as shown in table 6 for all treatments.

TABLE 5.-Rating of 32 avocado varieties in accordance with the mean of a combined index value which generalizes their performance under all different treatments of refrigerated storage ${ }^{1}$

\begin{tabular}{l|c||l|c}
\hline \multicolumn{1}{c|}{ Variety } & Mean index & \multicolumn{1}{|c|}{ Variety } & Mean index \\
\cline { 2 - 4 } Fuerte 6 & 615 & Utuado & 285 \\
PRRA 18 & 579 & Semil 23 & 267 \\
Gripiña 5 & 460 & Isabela 147 & 243 \\
Semil 37 & 455 & Semil 26 & 238 \\
Semil 44 & 440 & Semil 38 & 238 \\
Do. & 431 & Semil 11 & 198 \\
Semil 47 & 431 & Gripiña 1 & 192 \\
Semil 34 & 412 & Gripiña 9 & 186 \\
Isabella 111 & 410 & Gripiña 12 & 179 \\
Semil 39 & 409 & Winslowson & 177 \\
Semil 31 & 406 & Donaldson & 164 \\
Meléndez 2 & 405 & Gripiña 2 & 162 \\
Vannel late & 399 & Gripiña 9 & 157 \\
Castañer & 376 & Gripiña 2 & 145 \\
Semil 41 & 362 & Nabal & 132 \\
Semil 44 & 352 & Isabela 138 & 131 \\
Gripiña 7 & 344 & W.I. sd. 28 & 88 \\
Semil 43 & 334 & W.I. sd. 14 & 68 \\
\hline
\end{tabular}

14 indices of repeated tests involving 3 varieties are also shown.

This refrigeration tolerance index has the advantage of not being greatly affected if some treatment is lost through accident or malfunction of equipment. The index may be based on the remaining available treatments and will probably come fairly close to the index that would have been obtained using data from all treatments. This is because fruit injury generally increases with length of treatment. Longer periods increase the combined index whereas greater injury lowers the index. The two largely tend to cancel out each other. Thus in table 4 it may be observed that at the lower temperature of $43^{\circ} \mathrm{F}$. all four treatments resulted in mean indices of close to 300 . At the higher temperature of $53^{\circ} \mathrm{F}$. the increased injury was not sufficient to cancel out the effect of increased time and the 
mean index for all clones rose linearly starting at 184 and increasing roughly 100 points each week. Accordingly, therefore, of the seven treatments given only two would be expected either to raise or lower the combined index consistently if omitted. The 1 week at $53^{\circ} \mathrm{F}$., when included, tends to lower the index and its omission would, therefore, be expected to raise it. The 3-week treatment at $53^{\circ} \mathrm{F}$. tends to raise the index and its omission would be expected to lower it.

Of course, all seven treatments should preferably be included for comparing all varieties. It has occurred to us, however, that for comparing only early varieties against each other a more precise relative rating would be

TABLE 6.-Cold-tolerance index and estimated maximum ripening period for 1 fruit of different avocado varieties under refrigeration at $43^{\circ}$ or at

$53^{\circ} \mathrm{F}$. for from 1 to 4 weeks

\begin{tabular}{|c|c|c|c|}
\hline \multicolumn{2}{|c|}{ Treatments } & \multirow{2}{*}{$\begin{array}{l}\text { Estimated maximum } \\
\text { ripening period for } 1 \\
\text { frujt (days) }\end{array}$} & \multirow{2}{*}{$\begin{array}{l}\text { Varietal cold tolerance } \\
\text { index }\end{array}$} \\
\hline Period & Temperature & & \\
\hline \multirow[t]{2}{*}{1 week } & $53^{\circ} \mathrm{F}$. & 10 & 0.333 \\
\hline & $43^{\circ} \mathrm{F}$. & 12 & .400 \\
\hline \multirow[t]{2}{*}{2 weeks } & $53^{\circ} \mathrm{F}$ & 16 & .533 \\
\hline & $43^{\circ} \mathrm{F}$. & 18 & .600 \\
\hline \multirow[t]{2}{*}{3 weeks } & $53^{\circ} \mathrm{F}$. & 22 & .733 \\
\hline & $43^{\circ} \mathrm{F}$. & 24 & .800 \\
\hline 4 weeks & $43^{\circ} \mathrm{F}$. & 30 & 1.000 \\
\hline Total. & & & 4.399 \\
\hline Mean. . . . . . . . & & & 0.628 \\
\hline
\end{tabular}

achieved by using only the data from the first 2 weeks of storage for calculating the refrigeration-tolerance index. The reason for this is the basic concept that the range of testing treatments given should exceed but slightly the tolerance range of the fruit being tested. These early varieties all gave a mean index of less than 200 . Normally varieties of such low tolerance would rate an index of 0 in treatments lasting 3 weeks or more. The use of data from 3- and 4-week treatments would provide an opportunity for some freak fruit or some possible misinterpretation of symptoms to register a few points not strictly merited by the variety. Therefore, we also propose a supplementary, early-variety index of refrigeration tolerance for comparing early varieties only, based on their performance during the first 2 weeks of cold storage exclusively.

Table 5 shows, by order of performance, all of the fruit-sets tested and their corresponding refrigeration tolerance indices. 
The following tabulation shows, by revised order of performance, all the 11 early varieties rated according to the early-variety indices, based exclusively on their performance during storage for the first 2 weeks:

\begin{tabular}{lccc}
\multicolumn{1}{c}{ Variety } & Mean index & Variety & Mean index \\
Winslowson & 214 & Gripiña 2 & 162 \\
Isabela 138 & 198 & Gripiña 9 & 157 \\
Nabal & 197 & Gripiña 2 & 145 \\
Gripiña 9 & 186 & W.I. sd. 28 & 88 \\
Gripiña 12 & 179 & W.I. sd. 14 & 68 \\
Donaldson & 164 & &
\end{tabular}

\section{CLONAL PERformanCE}

With regard to the performance of our selected varieties we should like to point out the following highlights:

The two varieties of highest refrigeration tolerance, Fuerte 6 and PRRA 18, have serious defects which make them undesirable. Fuerte 6 is highly susceptible to anthracnose infection of the fruit and has a watery taste in wet years. PRRA 18 is red in color and also frequently has a watery taste.

Among the varieties with indices of 400 or better are included some of our best selections like Semil 34 and Gripiña 5, Semil 31, Semil 44, and Meléndez 2. All are late varieties and include both A and B flower types.

Of the medium-late varieties we were disappointed in the poor performance of Gripiña 12, which is otherwise excellent.

Our earliest varieties still remain to be tested for cold tolerance.

\section{SUMMARY}

A method is described for obtaining a refrigeration tolerance index for avocado varieties. This index reflects the generalized performance of a total of 35 avocado fruits, 5 of which are subjected to each of 7 different refrigerated treatments. The treatments consisted of $1,2,3$ and 4 weeks of storage at a mean temperature of $43^{\circ} \mathrm{F}$. and 1,2 , and 3 weeks at a mean temperature of $53^{\circ} \mathrm{F}$.

A total of 36 sets of fruits were tested and indexed accordingly. The resulting indices reflect marked clonal differences in cold tolerance, and suggest fairly consistent performance within the clone.

Indices are shown for 32 varieties, most of which are local selections, but which include 4 more or less standard varieties.

\section{RESUMEN}

Se describe un método para obtener un índice en cuanto al comportamiento de cada variedad de aguacate bajo estudio después que se sometió la fruta a refrigeración. El índice refleja el comportamiento de 35 frutas, en promedio, de las cuales cinco se incluyeron en cada uno de los siete 
distintos tratamientos de almacenaje bajo refrigeración. Los tratamientos fueron de 1, 2, 3 y 4 semanas de almacenaje a una temperatura promedio de $43^{\circ} \mathrm{F}$ y de 1,2 y 3 semanas de almacenaje a una temperatura promedio de $53^{\circ} \mathrm{F}$.

En total se sometieron 36 grupos distintos de fruta a estas pruebas y se calcularon los índices correspondientes. Los índices demostraron que hubo una gran diferencia en el comportamiento de las distintas variedades. También hubo ligeras indicaciones de que la diferencia sea poca en cuanto al comportamiento de las frutas de la misma variedad procedente de distintos árboles.

Se incluyen los índices de 32 variedades de aguacates, las cuales en su mayoría son selecciones locales, pero que incluyen también cuatro variedades que también se cultivan en Florida y California.

\section{LITERATURE CITED}

1. Higgins, J. E., Hunn, C. J., and Holt, V. S., The Avocado in Hawaii, Bul. 25, pp. 1-48, Hawaii Agr. Exp. Sta., 1911.

2. Lyle, R., Cold Storage Experiment with Florida Avocados, Fla. Agr. Exp. Sta. Mimeo. Circ., Dept. of Hort., 1933.

3. Lynch, S. J., and Stahl, A. H., Studies in the Cold Storage of Avocados, pp. 79-81, Fla. State Hort. Soc. proc., 1939.

4. Overholser, E. L., Cold Storage Behavior of Avocados, pp. 32-40, Calif. Avocado Assoc., Ann. Rep. 1924-25.

5. Wardlaw, C. W., and Leonard, E. R., the Storage of Avocado Pears, Imperial College of Trop. Agr. (Trinidad), Low Temperature Research Station Memoir, 1, March 1985. 